\title{
تصميم و تقنين اختبار لتقييم مستوى الأكرة العاملة
}

\begin{abstract}
مقدمة
الذاكرة العاملة إلى قدرة الفرد على وبلى

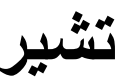

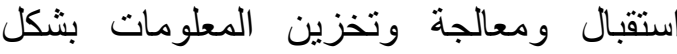

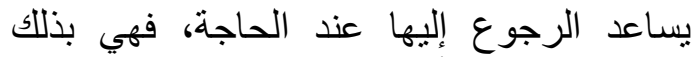

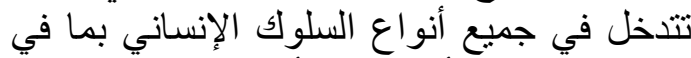

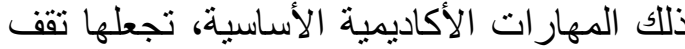

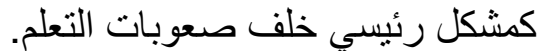

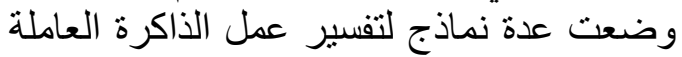

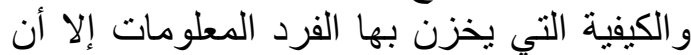

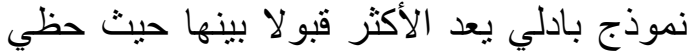

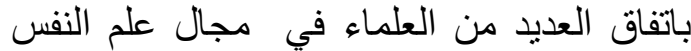

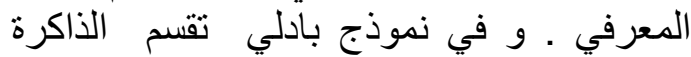

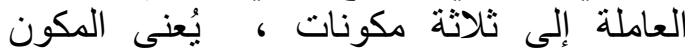

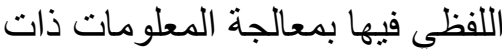

\section{Abstract}

The objective of the current study is to design a test to assess the level of working memory based on four dimensions (verbal component, visuo_spatial loop, executive control and episodic buffer). The sample study consisted of (90) students from second and third primary school. The result of the study have shown a good internal consistency in correlation between items and their dimension $(r=0.58-0.90)$ dimensions and the total score of the scale $(r=0.68-0.94)$ significant at $(p<.01)$ while the stability of the test amounted to (0.85).

الطابع اللفظي في حين تهتم الخلقة البصرية المكانية بمعالجة وتخزين المعلومات ذات
\end{abstract}


الطابع البصري المكاني من صور و مواقع واتجاهات، إضافة إلى معالجة الصور

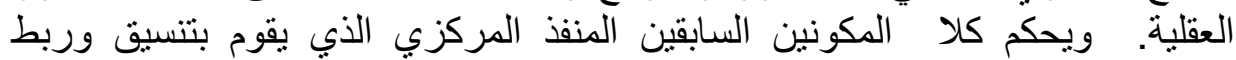

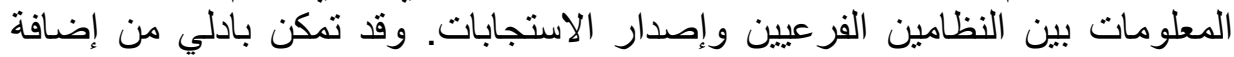

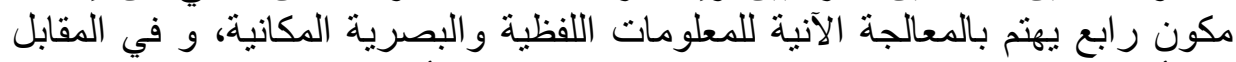

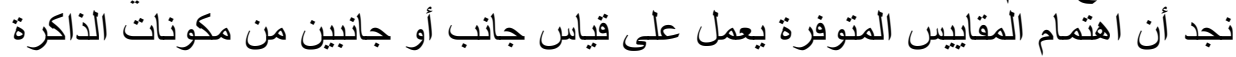

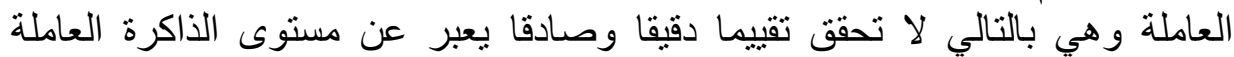

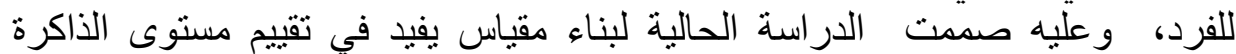

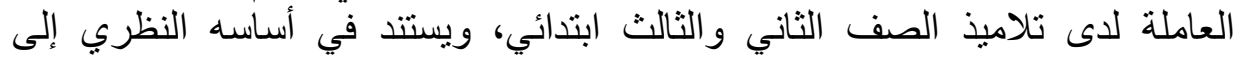

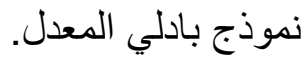

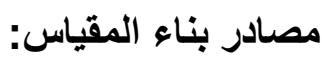

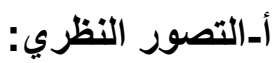

تعد الذاكرة من أهم الوظائف النفسية لدى الإنسان، تظهر في مختلف مجالات

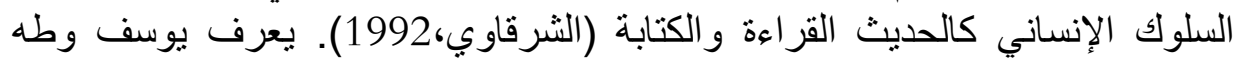

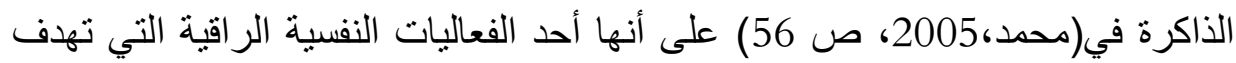

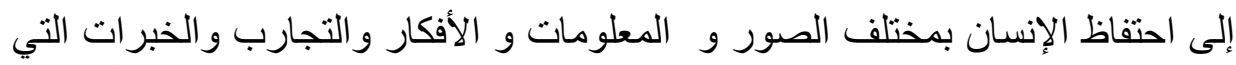

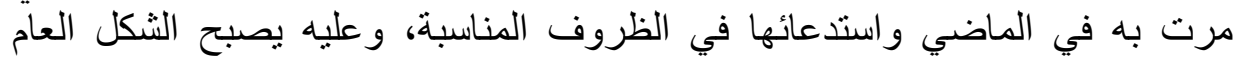

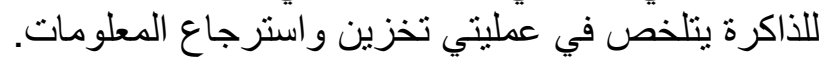

ويجمع علماء النفس المعرفي على وجود ثلاث مكونات رئيسية للذاكرة، تتعلق

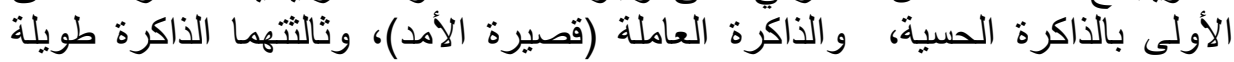

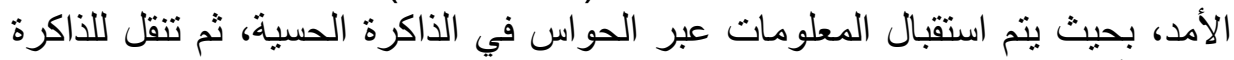

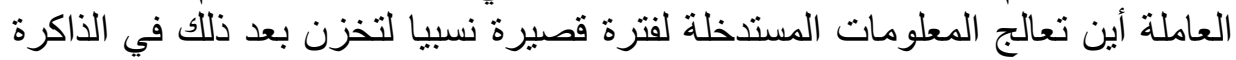

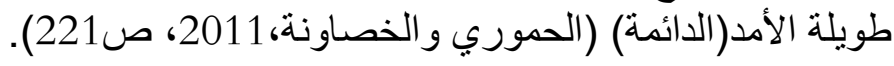

ويعرف (Baddeley (1992) الذاكرة العاملة بذلك المخزن المؤقت لكمية محدودة

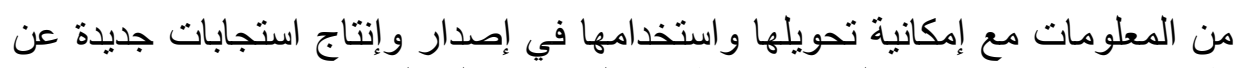

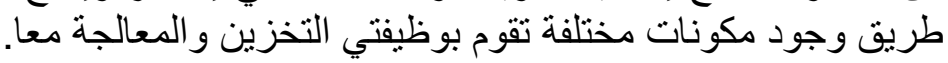

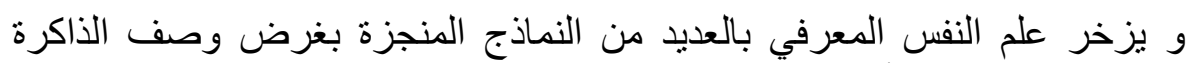
العاملة ومكوناتها، يعود أبرزهالَّل:

نموذج اتكنسون وشيفرن Atkinson\&shifrin model (1968): يركز هذا

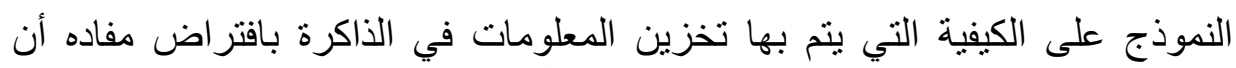
المعلومات يتم معالجتها وتخزينها في ثلاث مر احل منسلسئة:

$$
\text { - الذاكرة الحسية (المسجل الحسي) }
$$




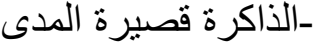

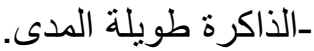

كما توجد ثلاثة أثكال لأنو اع المعالجة ضمن هذا النموذج نذكر ها فيما يلي:

المعالجة المادية: تعالج فيها المثيرات البصرية كالصور و المادة المكتوبة. المعالجة السمعية: ويتم من خلالها معالجة المثيرات الصوتية المتمثلة في الحروف و الكلمات المسمو عة و إيقاعها.

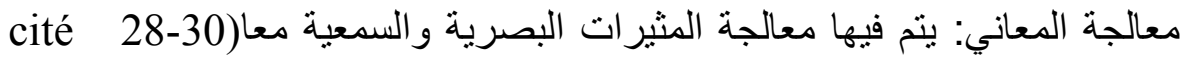
(dans :Loisy, 1998,pp

نموذج بادلي و هيتش الأول (1974) Baddeley\&Hitch : افترض كل من بادلي وهيتش وجود ثثلاثة مكونات للذاكرة العاملة ينرأسها المكون التنفيذي المركزي المئي

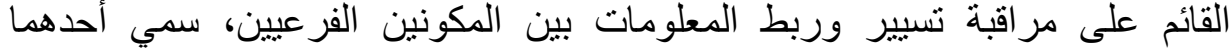
بالمكون البصري المكاني و الثاني بالمكون اللفظي.

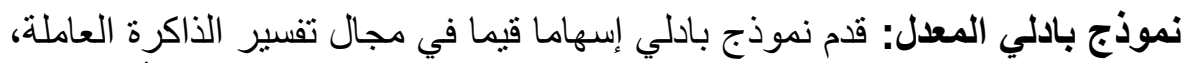

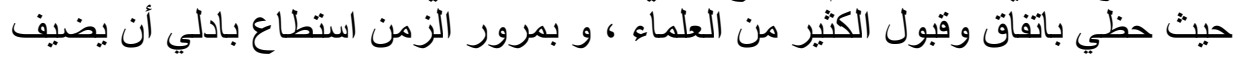

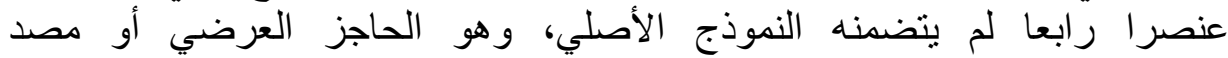

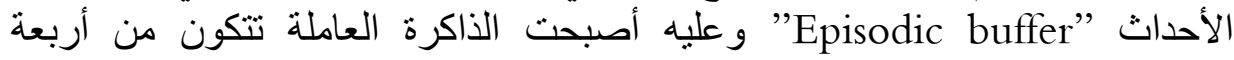
مكونات نتناولها بشيء من التفصيل في الآتي:

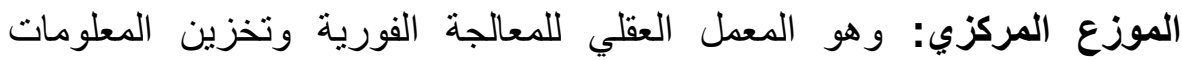

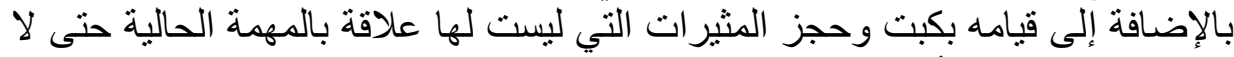
تؤثر على مستوى الأداء وتتلخص وظائف المنفذ المركزي في: -انتقاء المعلومات(فلترة).

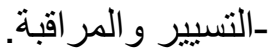
-ربط المعلومات في المكونين الفرعيين. ـالتنسيق و الربط بين المعلومات في النظامين الفر عيين و الذاكرة طويلة الأمد. ـالتحديث المستمر لمحتوى الذاكرة العاملة بناء على معطيات جديدة سو اء كانت من الذاكرة طويلة المدى أو من المدخلات الحسية. المكون البصري- المكاني: يتعامل هذا القسم مع المعلومات البصرية المكانية،

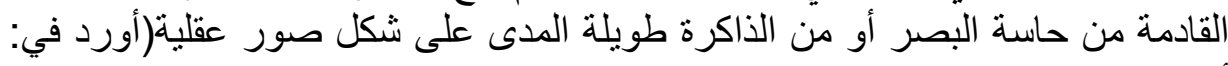

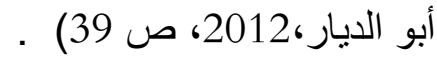


كما يعطي هذا المكون تفسيرا لكيفية التوجه المكاني وحل المشكلات البصرية

و المكانية (الثبيتي،2012، صاكية صنية) وحسب بادلي(2000) فيعد المكون البصري-

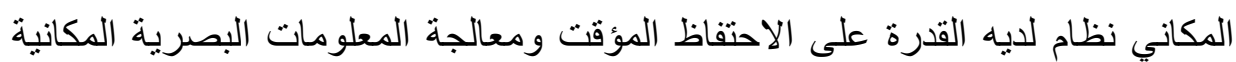

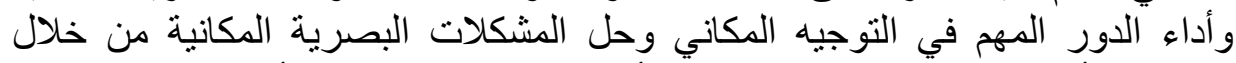

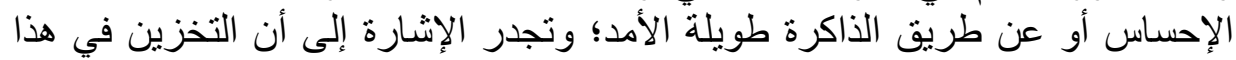

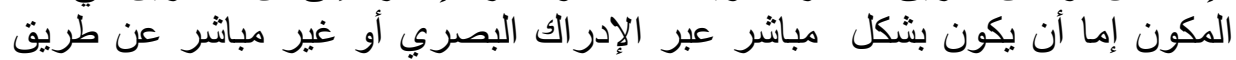

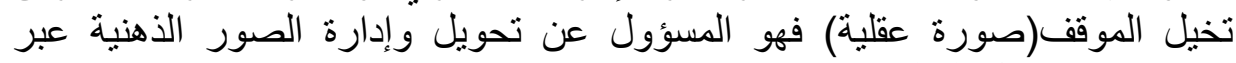
الوصف و التمثل العقلي والبحث عن الصور (Mario,2010,p13)

المكون اللفظي: يهتم بتخزين المعلومات اللفظية المعروضة سمعيا/بصريا وهو

بذلك ينقسم إلى:

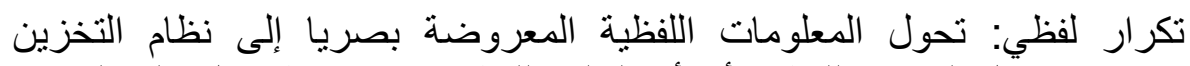

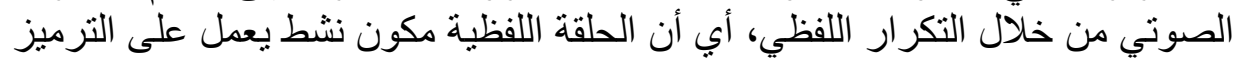

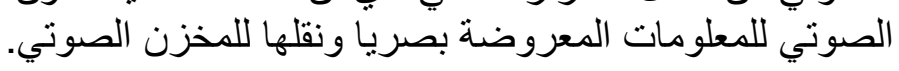

المخزن الصوني:يخزن المعلومات المعتمدة على الكلام اعتمادا لغويا في ثلاثة مر احل: - n

ـ ـ السجل الحسي: استدخال المعلومة مباثرة من حاسة السمع. ـ التكرار اللفظي: النطق الداخلي للمعلومات.

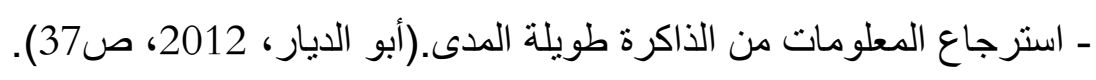
ويؤثر على عمل هذا النظام:

التشابه الصوتي: فمستوى استرجاع الوحدات غير المتشابهة يكون منخفضا. طول الكلمة: الاسترجاع المتتابع للكلمات القصيرة يكون أحسن من الكلمات الطويلة.

مصد الأحداثم:Episodic buffer: هو نظام مؤقت لتخزين المعلومات مختلفة

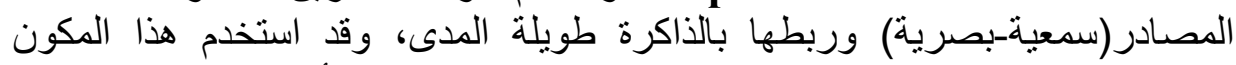

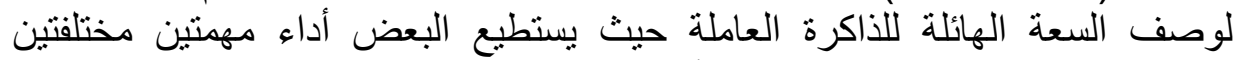

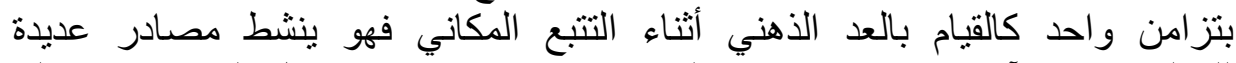

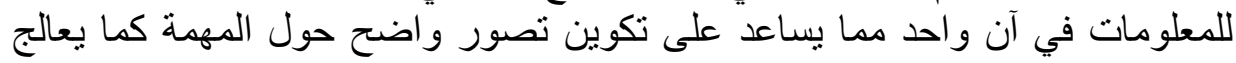

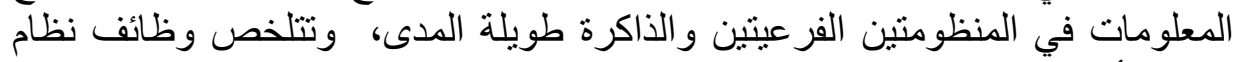
مصد الأحداثّ في النقاط التالية: ـ تخزين المعلومات متعددة المصادر . 
- ربط المعلومات بين المكونين الفر عين و الذاكرة طويلة المدى. - يقدم نموذجا واضحا للمهمة ومن ثم معالجتها.(أبو الديار،2012، ص239) الذاكرة العاملة و صعوبات التعلم:

مصطلح صعوبات التعلم مفهوم واسع يعود إلى مجموعة منباينة من الإضطربات الكاب التوات

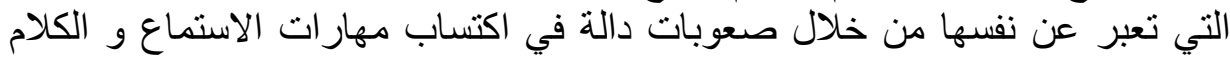
و القراءة والكتابة والاستدلال أو العمليات الحسابية. ويفترض أنيات أن تكون نتيجة لخلل

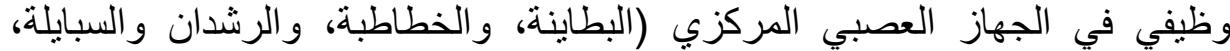

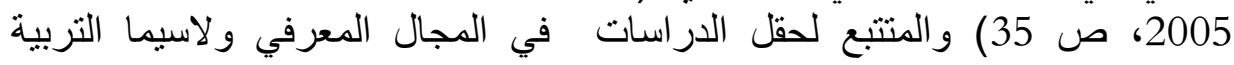
الخاصة سيلاحظ تداخلا كبيرا بين الذاكرة العاملة وصعوبات التعلم، بحيث خلص كل

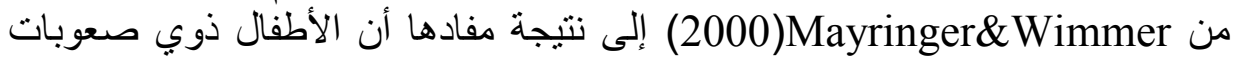

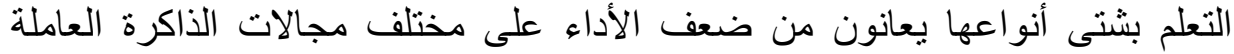
مقارنة بغير هم من الأطفال ذوو المشكلات السلوكية أو العاطفية. وتعد الذاكرة السمعية

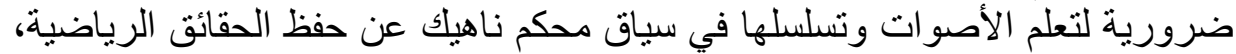

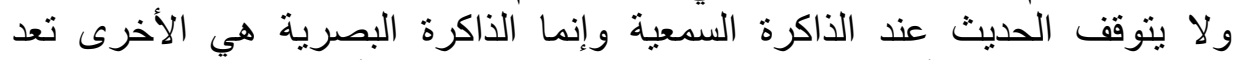

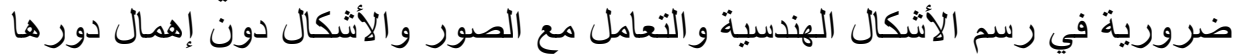

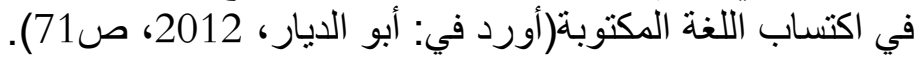

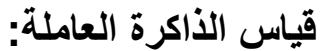

ذكر بادلي أهمية المكون الفنلوجي في اكتساب اللغة الثانية عند الأطفال و عمل على الفي

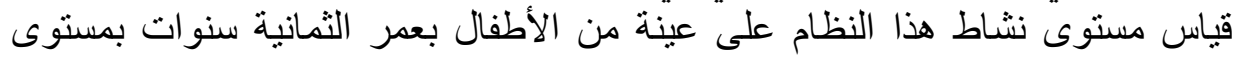
ذكاء طبيعي مستخدما في ذلك بطارية اختبار ات الذاكرة وتتنتمل على مهمتين:

الاسترجاع العكسي: فيه تعرض على المفحوص سمعيا (8) كلمات ويطلب منه

استرجاعها بشكل عكسي.

معنى الكلمات: تعرض على المفحوص(8) كلمات سمعيا بلغة أجنبية مع ما ير اد فها

Anderson, Baddeley, and ().اللغة الأولى ويطلب من المفحوص استرجاعها كما اهتم بالجانب التخيلي بمعنى استحضار الصور العناء العقلية (Eysenck, 2009,p 46

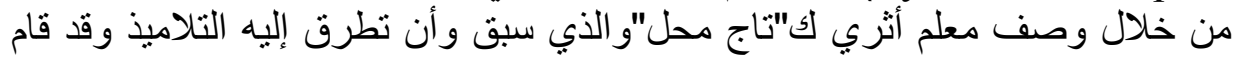
ورن Finck\&Slayton

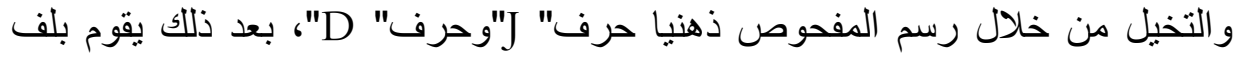
الحرف الأخير ناحية اليسار بدرجة 90ه ثم وضعه فوق الحرف الأول والإجابة الصحيحة على الشكل المحصل في الأخير ستكون المظلة. 
في شكل مماتل تقدم للمفحوص4، 6 أو 8 وحدات مثل المربع، المثلث أو الدائرة ويقوم المفحوص ذهنيا بتوظيفها في استخدام شيء مهم و تسميته (cité dans : Majrus, sd, $p$ و وهاك مهمة تقليدية تستخدم في قياس الذاكرة العاملة تقدم فيها مجمو عة من الأرقام أو الكلمات بطول متنامي والمطلوب هو استرجاعها بشكل متسلسل بمعدل ثانية لكل وحدة.

وكثير ا ما استعمل اختبار Wichsler و Corsi لقياس المكون البصري المكاني من

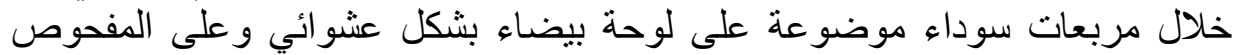
استرجاع أماكن. اتول (cité dans: Mario,2010,p15)

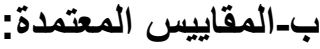

-اختبار ات الذاكرة العاملة(فاضل،2006): يحتوي على اختبار مدى الجمل، اختبار

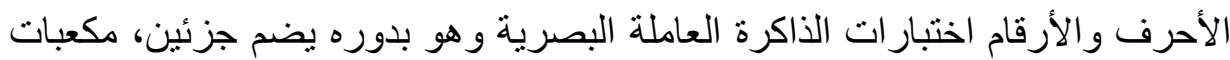
كورسي Corsi block test واختبار التعرف التعرف على الوجوه.

ـ اختبار الذاكرة (العايد،2007): يشتمل على ثنلاث اختبار ات فرعية صممت لقياس

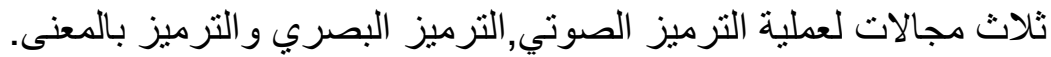
- بطارية مهام الذاكرة العاملة(سلمان،2010): وفيها يقوم الحاسب بتقديم منبهات

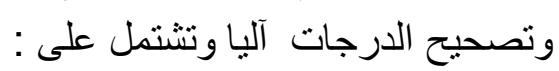

مهام الذاكرة العاملة اللفظية: مهمة التذكر السمعي، مهمة العد، مهمة تذكر الأرقام بشكل عكسي.

مهام الذاكرة العاملة البصرية المكانية: مهمة استدعاء الثكل المختلف، مهمة الأراجوز، مهمة المدى المكاني. المعامة المهيرة

- اختبار الذاكرة العاملة المقنن للأطفال( أبو الديار، 2012): يتكون من ستة

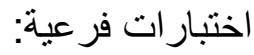

اختبار الذاكرة المكانية المتسلسلة، اختبار الذاكرة المكانية العكسية، اختبار إعادة

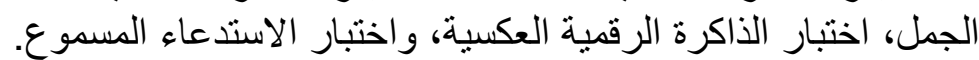

- اختبار Corsi لقياس مهام الذاكرة البصرية المكانية: وهو يتكون من لوح به (09) مكعبات موضو عة على لوحة بيضاء و على المفحوص النقر على نفس المكعبات

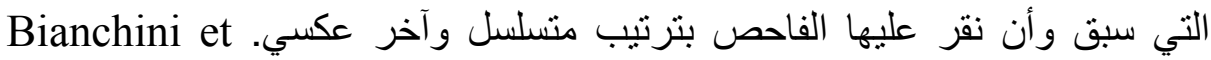
al,2008 
-اختبار وكسلر(النسخة الر ابعة):لا يقتصر اختبار وكسلر على مجرد تقديم درجات

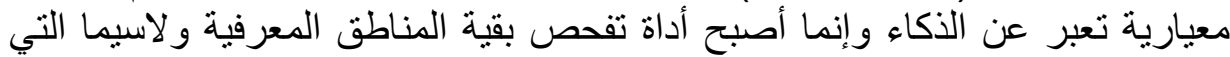

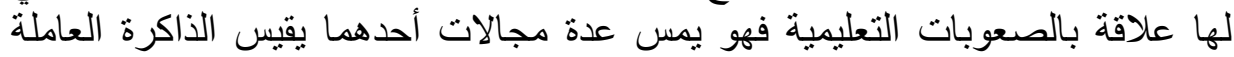

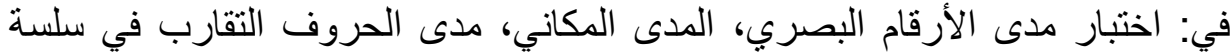
حرف_عدد، الحساب الكتابي(Wechsler,2003) -اختبار Stroop:اختبار معد لقياس الانتباه الانتقائي عند الأفر اد. -اختبار(الخطيب،2012) وهو معد لقياس الأنماط الثلاثة للذاكرة العاملة(التنفيذي، اللفظي و البصري_المكاني). أبعاد المقياس: على ضوء الطرح النظري السابق، قامت الباحثة بتقسيم المقياس البقاس

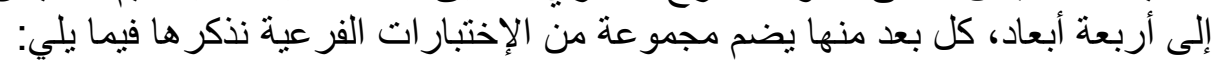

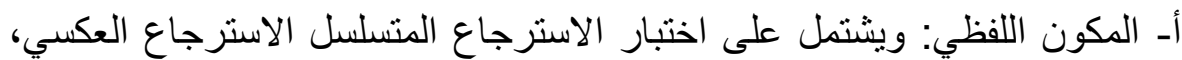

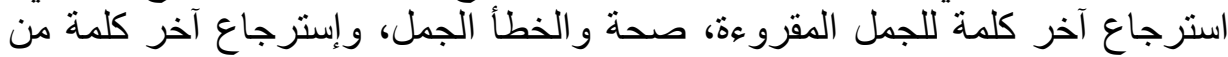

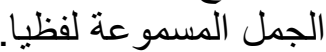

ب-المكون البصري المكاني: يضم اختبار النقر المتسلسل، النقر العكسي، نقل

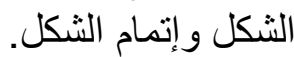
ج- المنفذ المركزي: يتكون من اختبار اتمام الكلمات، الأعداد الزوجية، واختبار الربط. د- مصد الأحداث: يضم اختبار الكلمة وموقعها، أرقام الحيز الصغير وموقع

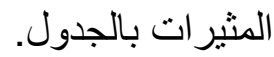

تطبيق المقياس وكيفية تصحيحه: بطبق اختبار الذاكرة العاملة بشكل فردي، حيث إثئ بلغ منوسط مدة التطبيق على عينة التقنين(15) دقيقه علما أن مهام الذاكرة العاملة تتطلب أداء المهمة أو استرجاع المادة بعد سماعها مباشرة. أ- خصائص المفحوصين: يستخدم هذا الاختبار للكثف عن مستوى الذاكرة

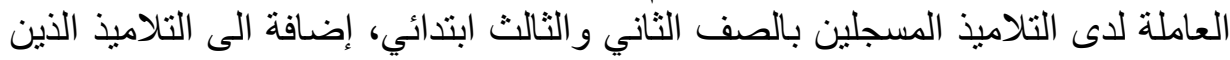
يعانون من صعوبات التعلم. ب- طريقة الإجابة: يتكون اختبار الذاكرة العاملة من(15) اختبار ا فرعيا تختلف فيه التعليمات وطريقة الأداء على المهمة بما في ذلك طريقة التصحيح لبنود الاختبار و الجدول التالي يفسر ذللك جدول رقم(01) يوضح أبعاد الاختبار مع الاختبار ات الفرعية وكيفية التصحيح. 


\begin{tabular}{|c|c|c|c|}
\hline الارجة & التعليمة & 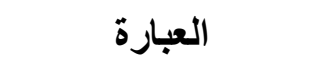 & 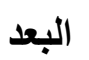 \\
\hline 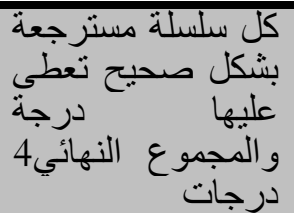 & 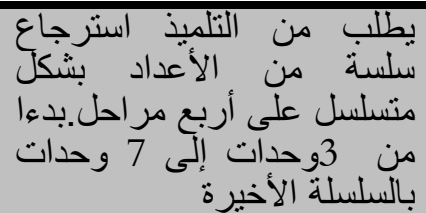 & الاسترجاع المتسلسل & \\
\hline 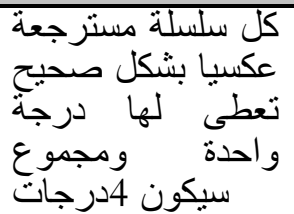 & 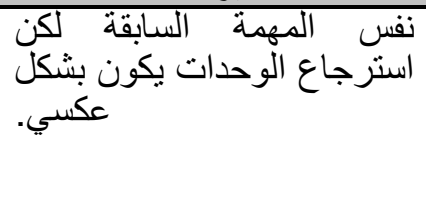 & الاسترجاع العكسي & \\
\hline 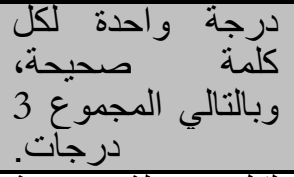 & 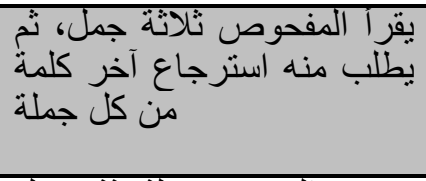 & استرجاع اخر كلمة & \\
\hline 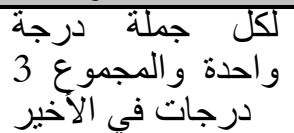 & 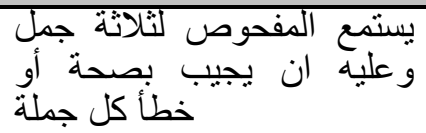 & صحة وخطأ الجمل & \\
\hline 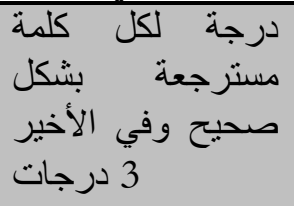 & 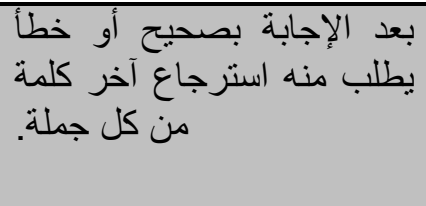 & استرجاع آخر كلمة & \\
\hline \multicolumn{4}{|c|}{ الارجة الكلية لبعد المكون اللفظي: (17) درجة } \\
\hline 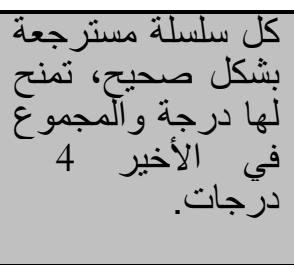 & 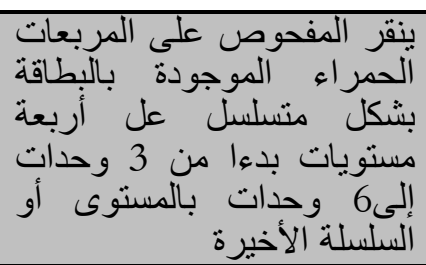 & النقر المتسلسل & \\
\hline 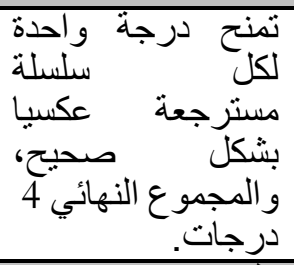 & نفلى المربعات بـابكون لكن بشكل النقر & النقز العكسي & \\
\hline 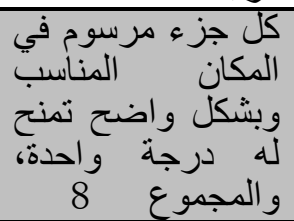 & 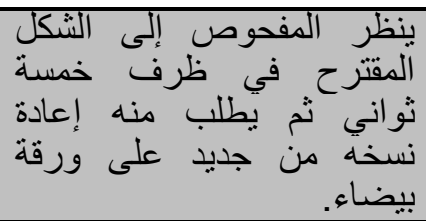 & نقل الشكل & \\
\hline
\end{tabular}




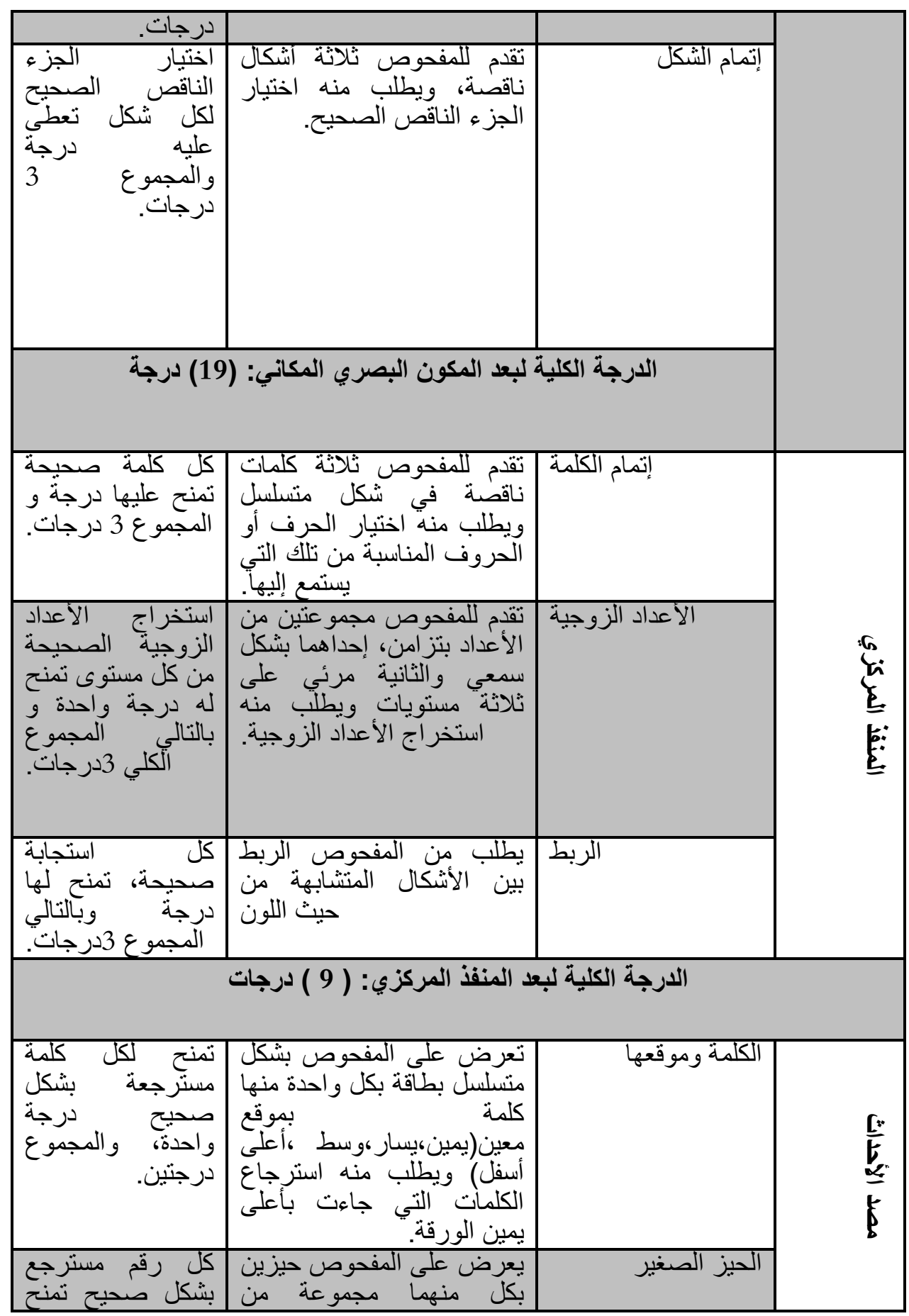




\begin{tabular}{|c|c|c|}
\hline 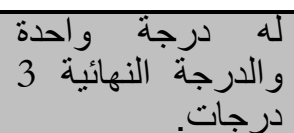 & 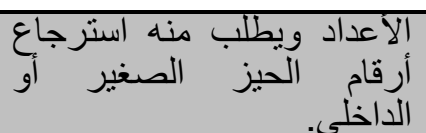 & \\
\hline 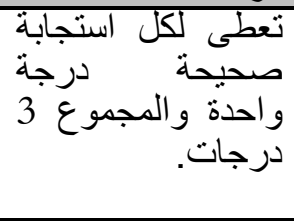 & 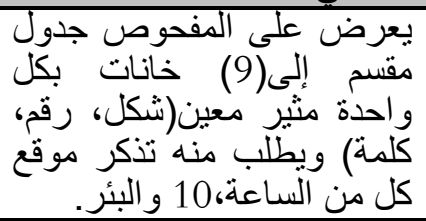 & 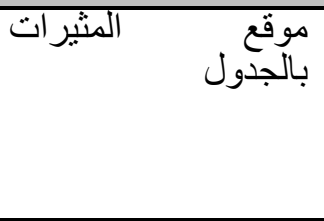 \\
\hline \multicolumn{3}{|c|}{ الارجة الكلية لبعد مصد الأحداث: (8)درجات. } \\
\hline & ختبار الذاكرة العاملة: (53) & الدرجاً \\
\hline
\end{tabular}

ج- تفسير درجات الاختبار : تثير الدرجة التي يتحصل عليها المفحوص إلى خمسة

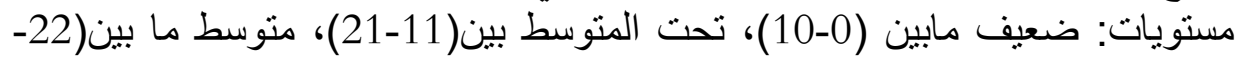

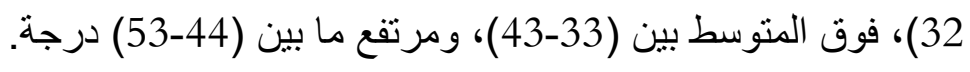
الخصائص السيكومترية للمقياس:

عينة التقنين: للتحقق من صدق وثبات الاختبار تم تطبيقه على عينة من تلاميذ

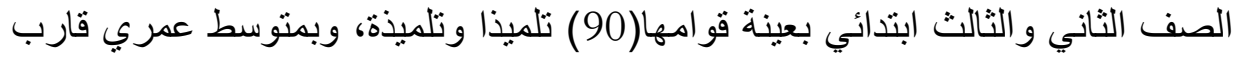
التسعة سنو ات بمعدل(8.73)سنة.

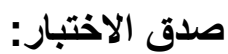

صدق الاتساق الداخلي: قامت الباحثة بحساب معامل الارتباط بين كل بند و الدرجة

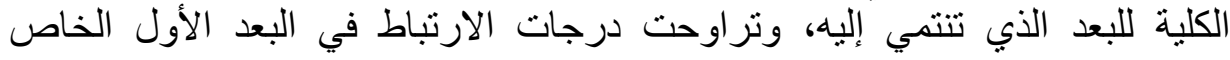
بالمكون اللفظي بين(0.73 و و0.88) عند مستوى دلالة (0.01).

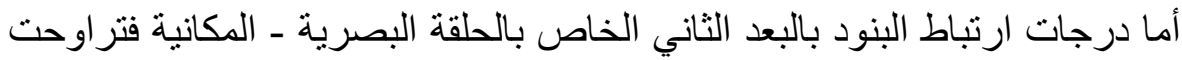

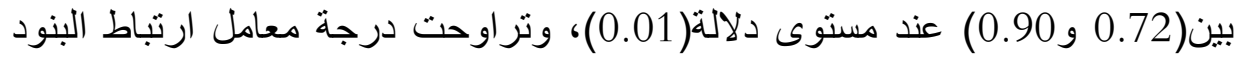

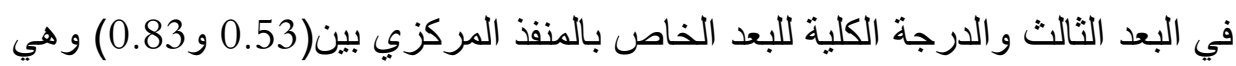
دالة عند مستوى(0.01).

وفيما يخص البعد الأخير الخاص بمصد الأحداث، فتراوحت درجة ارنباط بنوده بالدرجة الكلية(0.82 و و0.87) عند مستوى دلالة (0.01).

و وعن درجة معامل الارتباط بين الأبعاد فيما بينها والمقياس ككل فتراوحت بين(0.67 و0.94) و هي جميعها دالة عند مستوى دلالة (0.01). 
الصدق التميزي: من أجل حساب معامل الصدق التمبزي طبقت الباحثة الاختبار

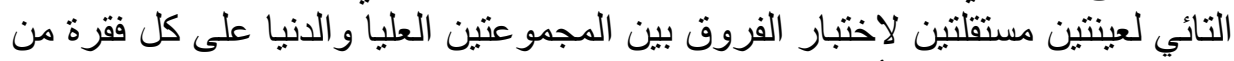

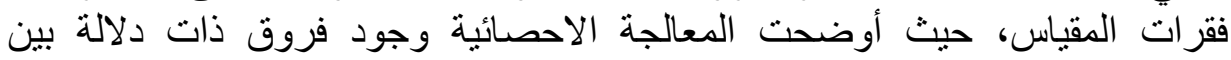

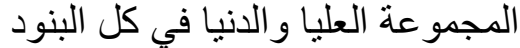

كما أظهر الاختبار في شكله العام قدرته على الته التمبيز بين المجموعة العليا والدنيا من حيث مستوى الذاكرة العاملة وهو مؤشر آخر آخر على صلى صدق الاختبار و والجدول التالي

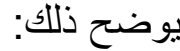

جدول رقم(02) يوضح الفرق بين درجات أفر اد المجموعة العليا والدنيا

\begin{tabular}{|c|c|c|c|c|c|}
\hline مستوى الدلاكة & "الجدولية & "المحسوبة & الالحعراف & الحستوسط & \\
\hline \multirow[t]{2}{*}{0.01} & \multirow[t]{2}{*}{2.68} & \multirow[t]{2}{*}{21.36} & 3.63 & 12.91 & الألجموعة \\
\hline & & & 4.61 & 38.54 & المجموعة \\
\hline
\end{tabular}

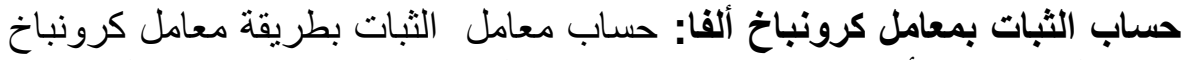

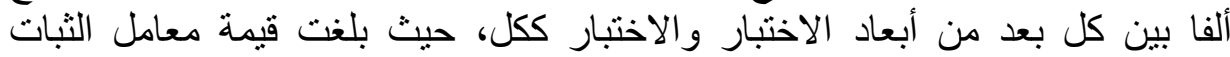
للمقياس ككل(0.93) أما ثبات أبعاد الاختبار فكان مقبو لا نر اوح بين(0.48) و و(0.82).

\section{حساب معامل الثبات بطريقة التجزئة النصفية:}

بلغت درجة ثبات الاختبار بطريقة التجزئة النصفية (0.85) وبعد تعديل النتيجة من

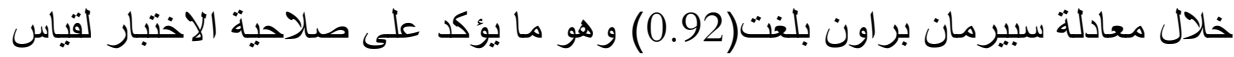
مستوى الذاكرة العاملة، أما درجة ثبات الأبعاد بعد التعديل فقد نراوحت بين(0.52

خاتمة

جاءت الدراسة الحالية لتقدم إسهاما يخدم مجال البحث في الذاكرة العاملة هذه أنهان

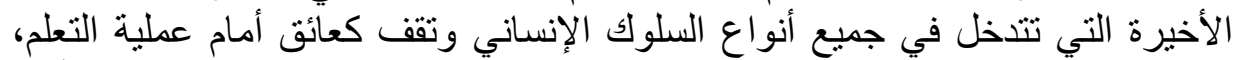

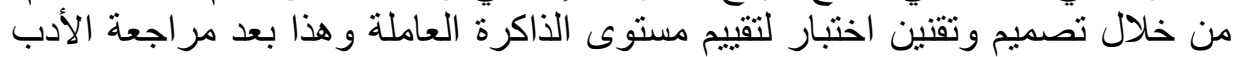

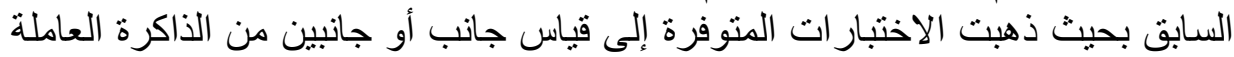
كالمكون اللفظي أو/ والمكون البصري المكاني دون التطرق إلى إلى قياس المكون الثالث

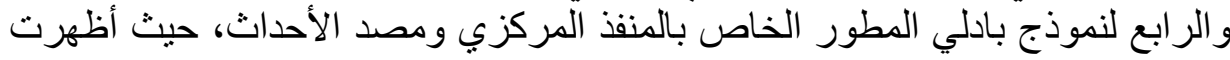


نتائج التقنين مؤشرات مقبولة تجعل الاختبار صالحا لقياس ما وضع لأجله و عليه

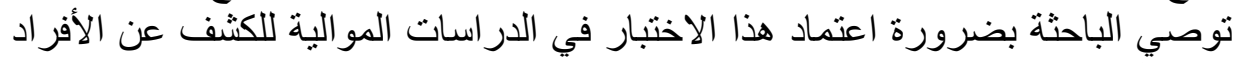
ذوي المسنويات المتدنية في الذاكرة العاملة . كما تقترح الباحثة أيضا تدعيم مسيرة البحث العلمي بانجاز بحوث في المحاور التالية:

ـ تقييم مستوى الذاكرة العاملة لدى المتمدرسين.

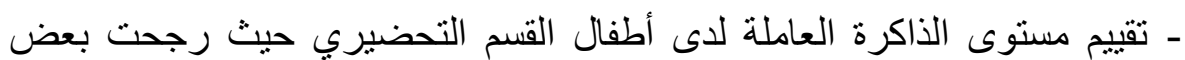
الدراسات وجود علاقة بين صعوبات التعلم في الطور الابتدائي وضعف مستوى لطع الذاكرة العاملة في القسم التحضيري. - إعداد بر امج تعليمية تغطي الجوانب الأربعة للذاكرة العاملة. - إعداد برامج تدريبية لرفع مستوى نشاط الذاكرة العاملة ولاسيما لدى التلاميذ القسم التحضيري.

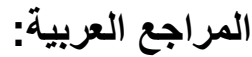
1.أبو الديار، مسعد.(2012). الذاكرة العاملة وصعوبات التعلم. الكويت: مركز تعليم وتقويم

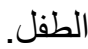
2.البطاينة، أسامة؛ و الخطاطبة، عبد الحمي؛؛ والرشدان، مالك؛ والسبايلة، عبد الحميد. (2005) ـ صعوبات التعلم: النظرية و الممارسة.عمان: دار المسيرة للنشر والتوزيع.

3.الثبيني، عادل.(2012).عمليات الذاكرة لدى طلاب المرحلة الثانوية والجامعية بلفئرة بمحافظة

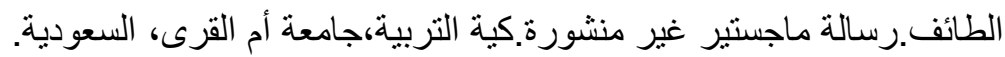

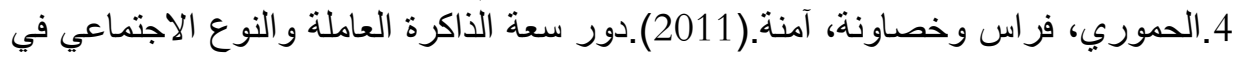

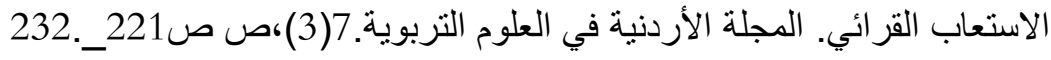

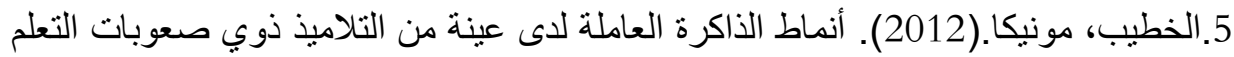

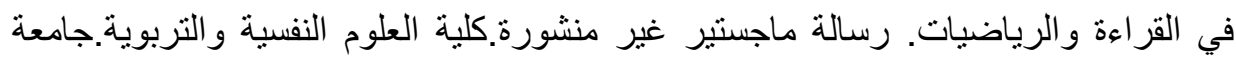

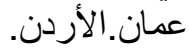
6.الشرقاوي، أنور ـ(1992). علم النفس المعرفي المعاصر .القاهرة:المكتبة الأنجلومصرية.

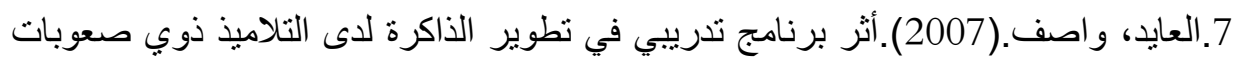

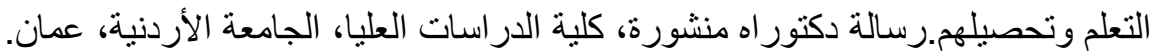

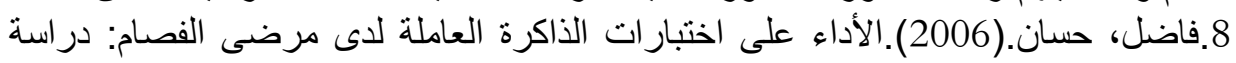
مقارنة.أطروحة دكتور اه غير منشورة.كلية الآداب. قسم علم النفس.جامعة القاهرة. 9.محمد، صالح.(2005).علم النفس اللغوي والمعرفي.عمان:دالئدار البداية. 
10.سليمان، عبد ربه.(2010). دور الذاكرة العاملة اللفظية والبصرية_المكانية في التنبؤ

بالتحصيل الدراسي لاى تلاميذ التعليم الأساسي.مجلة العلوم الاجتماعية،38(4).

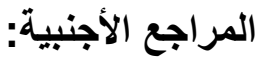

11.Anderson,M.,Baddeley,A.,\&Eysenck,M.(2009).Memory. USA: Psychology press.

12. Baddeley,A.(1992).Workingmemory.Science,newseries,255(5044),pp 556 559.

13. Baddeley,A.(2000).The episodic buffer:Anew component of working memory?.Trends in cognitive science, 4, pp417_423.

14.Bianchini,F.,Guarigila,C.,Iria,G.,Piccardi,L.,Ricci,M.,\&Zompanti,L.

(2008).Walking in the corsi test: Which type of memory do you need?.Neuroscience letters.432, pp127_131.

14.Loisy,C.(1998).La mémoire de travail visuo_sptial:Recherche d'un effet longueur de parcours. Thése du doctorat.Grenoble.Université Pierre Mendés. Paris.

15.Majerus,S.(sd).L'évaluation de la mémoire à court terme. Paris :Solal.

16.Mario,L.(2010).Mémoire de travail visuo_spatial et enfant TDA /H .Mémoire en vue de l'obtention du diplôme d'état de psychomotricien. Faculté de médcine.Paris.

17.Wechsler,D.(2003).Inteligence scale for children.USA:Pearson.

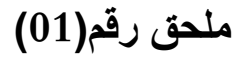

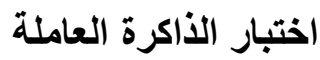

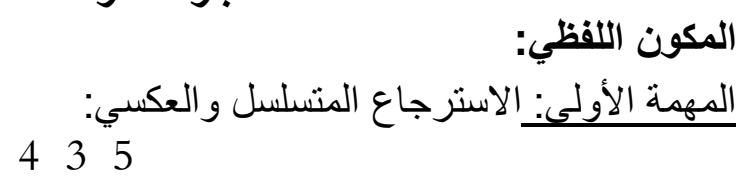

$\begin{array}{llllll}3 & 7 & 1 & 2 & 6\end{array}$

$\begin{array}{llllll}6 & 1 & 2 & 3 & 7 & 4\end{array}$

$\begin{array}{lllllll}1 & 9 & 6 & 8 & 5 & 2 & 3\end{array}$

تعليمات: يستمع المفحوص لمجموعة من الأرقام، ثم يطلب منه إعادتها بشكل متسلسل 
ثم بشكل عكسي. الدرجة:تعطى درجة واحدة لكل اجابة صحيحة (وحدة) و يوقف الاختئة واختبار بعد محاولتين خاطئتين متتاليتين، و الدرجة النهائية للمهمتين معا هي(08)

$$
\text { ألتهـد في دروسي }
$$

المهمة الثانية:

تعليمات:يقر أ المفحوص كل جملة و المطلوب منه في الأخير استرجاع آخر كلمة من كل عبارة في شكل متسلسل. تونة الارجة: تعطّى درجة واحدة على كل كلمة صحيحة و المجموع في النهائي(03)

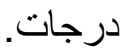

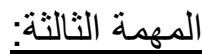

$$
\text { طعمل المزارع في المصنع الساة السرع من الأرنب }
$$

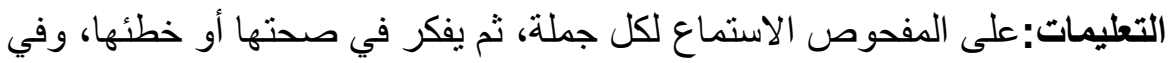
الأخير يسترجع آخر كلمة من كل عبارة.

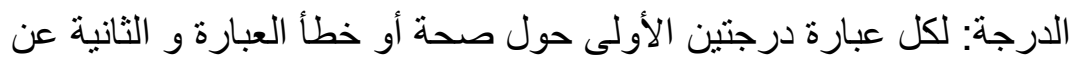
الاسترجاع الصحيح، و المجموع في الأخير(06) درجين الاول درات. المكون البصري المكاني:

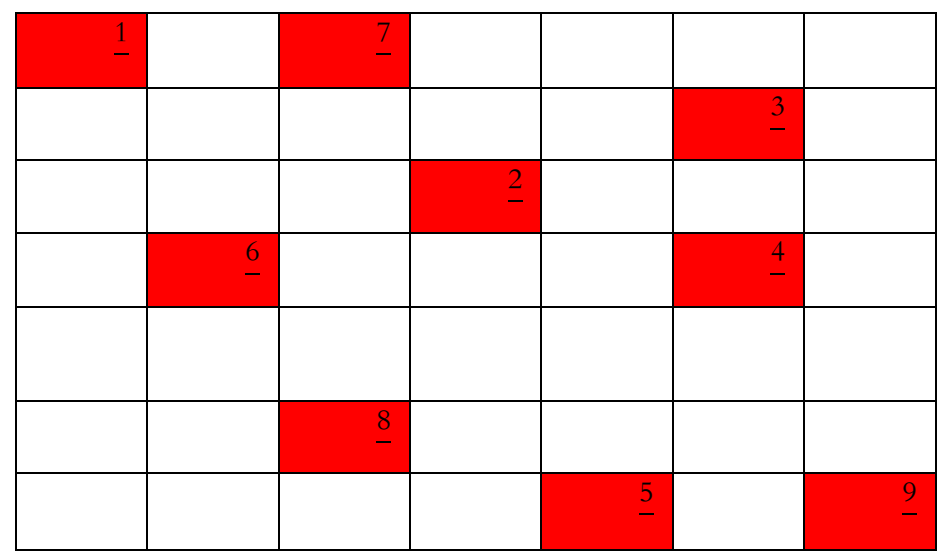
المهمة الأولى: 


$$
\begin{aligned}
& \text { أـالنقر على مربعات التالية بشكل متسلسل ثم بشكل عكسي: } \\
& 862 \\
& \begin{array}{llll}
6 & 8 & 4 & 7
\end{array} \\
& \begin{array}{lllll}
9 & 5 & 6 & 3 & 1
\end{array} \\
& \begin{array}{llllll}
1 & 7 & 6 & 5 & 2 & 9
\end{array}
\end{aligned}
$$

التعليمات: يقوم المفحوص بالنقر على نفس المربعات الحمر اء التي نقر عليها الفاحص

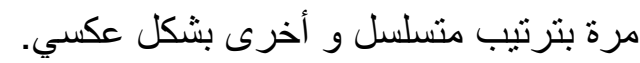
الدرجة: تقدم درجة واحدة على كل اجابة صحيحة و الدرجة النهائية تقدر ب(08) المهمة الثانية: نقل الثكل

التعليماثئيجركض الفاحص الرسم على المفحوص لمدة (05)ثواني و يطلب منه إعادة

$$
\text { رسمه على ورقة. }
$$
الدرجة:تعطى درجة على كل جز ء مرسوم بشكل صحيح و و اضح و الدرجة النهائية(08)

المهمة الثالثة: القدرة البصرية المكانية

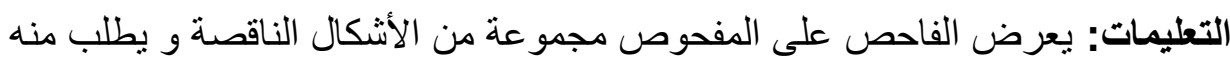
انتقاء الجزء الصحيح لإتمام الثكل وتسميته. 

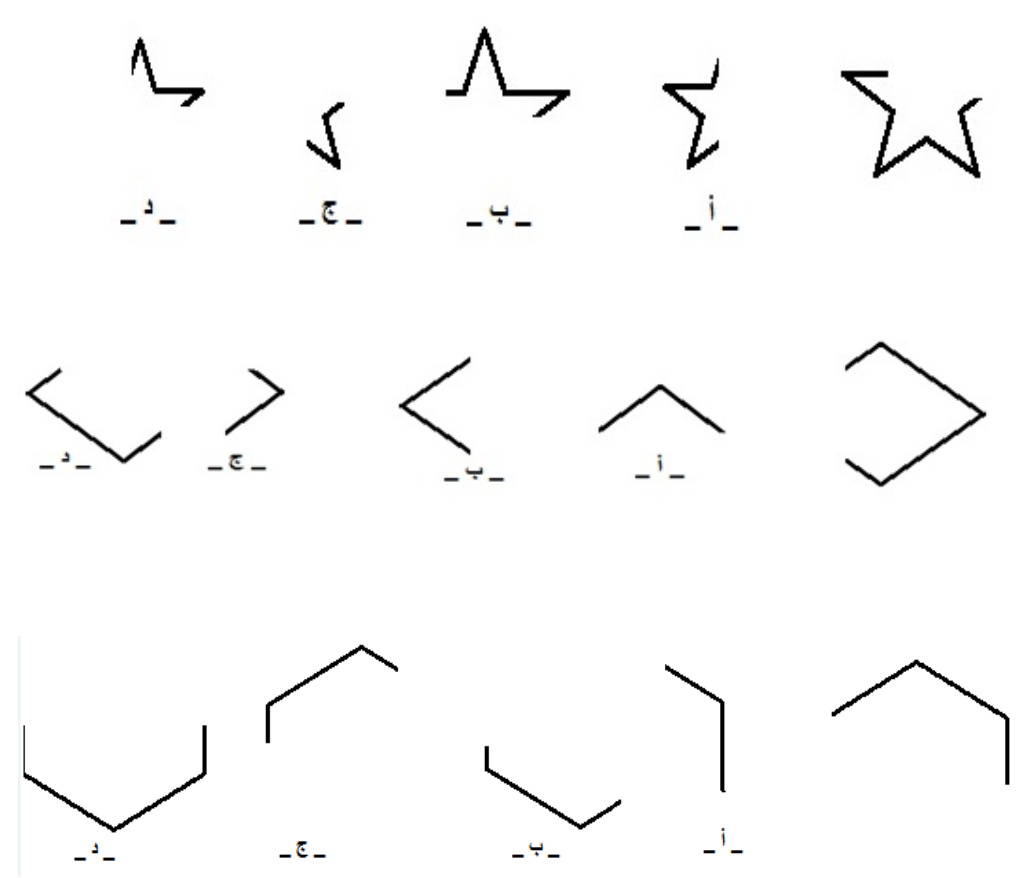

الدرجة: تعطى درجة واحدة على كل إجابة صحيحة و الدرجة النهائية(03)

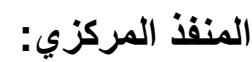

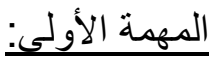

التعليمات: يعرض الفاحص على مفحوص كلمة ناقصة وفي نفس وقت يملي عليه مجموعة من الحروف وعليه اختيار الحرف المناسب لإتمام الكلمة:

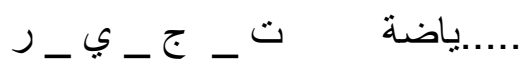

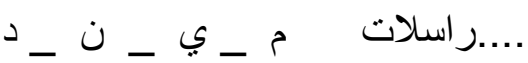

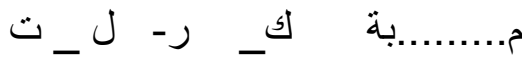

التعليمات: يعرض الفاحص على المفحوص مجموعة من الاعداد بصريا وفي نفس التس

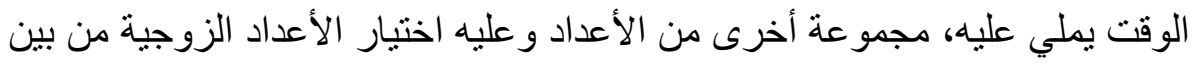
القائمتين . 


$$
\begin{array}{rrr}
1-6 & 3-5 & -5 \\
3 & -4-5 & 7-8 \\
3 & -5 & -1
\end{array}
$$

المهيمة الثالثة:

التعليمات: يعرض الفاحص على المفحوص مجموعة من الأشكال و يطلب منه الربط

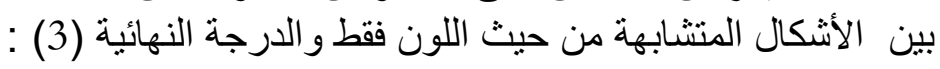
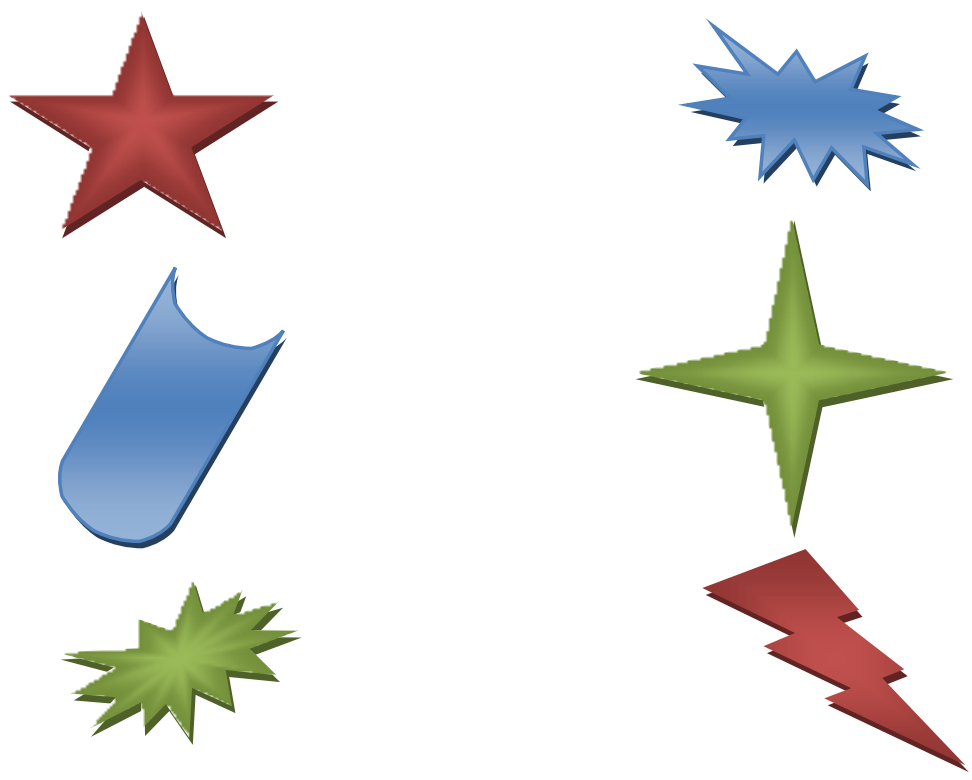

مصد الأحداث:

المهمة الأولي: الكلمة و موقعها

التعليمات: يعرض الفاحص على المفحوص كلمات في مو اقع مختلفة ( أعلى، وسط،

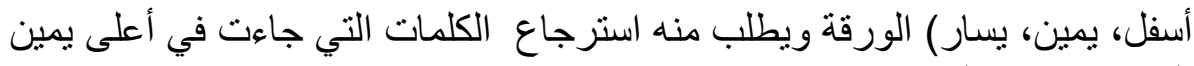

الورقة ودرجة النهاية هي(2) الورئة
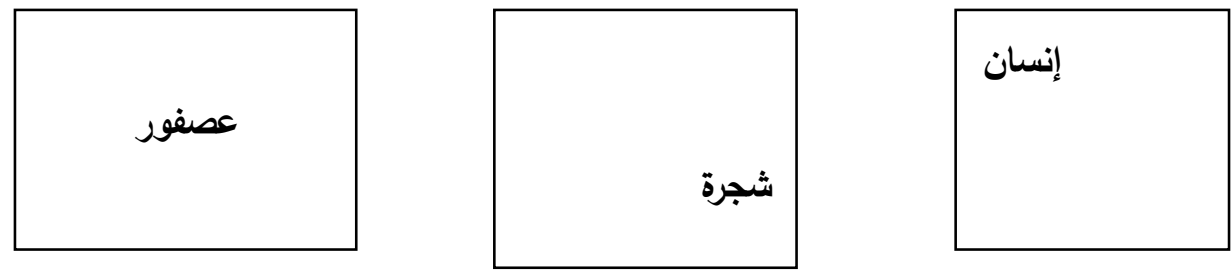

613 

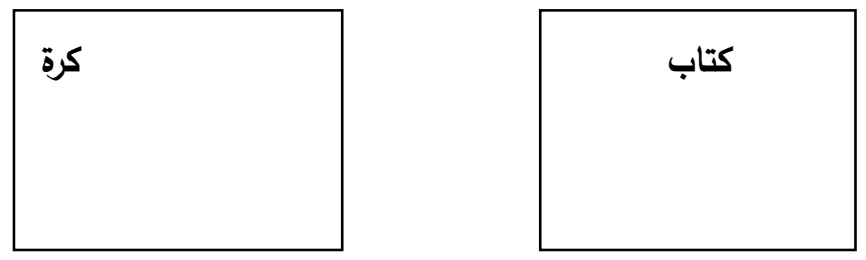

المهمة الثانية: التعليمات: يعرض الفاحص على المفحوص مجمو عتين بكل منهما أعداد و يطلب منه استرجاع الأرقام التي كانت داخل المجموعة الصغرى الصفي الدرجة النهائية(03)

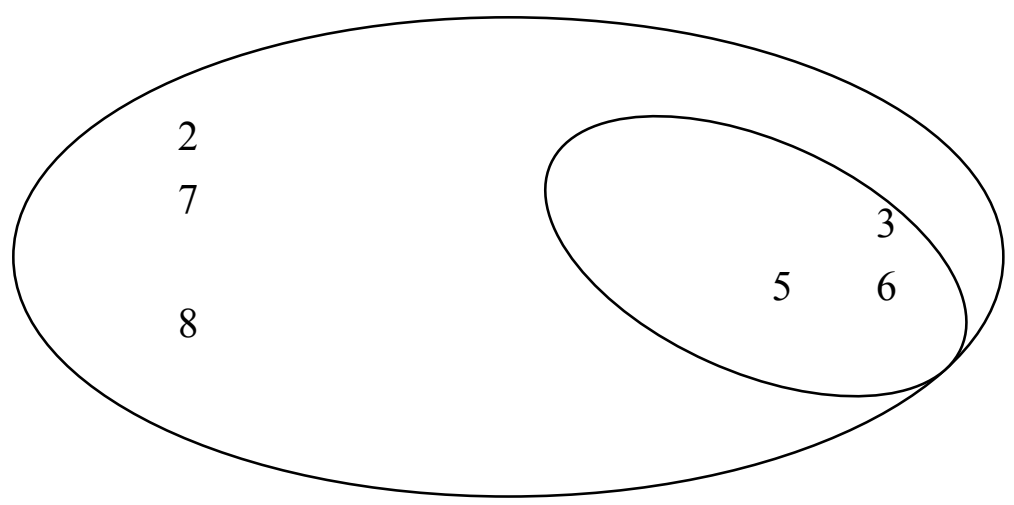

المهيمة الثالثة:

التعليمات: يعرض الفاحص على مفحوص جدول يتضمن أشنكال أرقام وكلمات ثم الثن

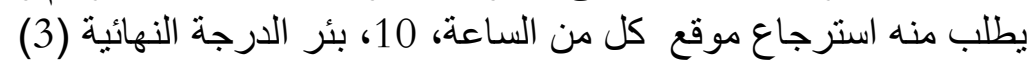




\begin{tabular}{|l|r|r|}
\hline بئر & (ألعاب \\
\hline 10 & 9 & \\
\hline & & \\
\hline
\end{tabular}

